\title{
Emerging Disease Burdens and the Poor in Cities of the Developing World
}

\author{
Tim Campbell and Alana Campbell
}

\begin{abstract}
Patterns of future urban growth, combined with advances in the treatment of traditional scourges of communicable diseases, will cause a shift in the burden of disease toward category 2 (noncommunicable) and 3 (injury) conditions over the next 30 years. Communicable diseases, particularly HIV/AIDs, will continue to be the most important killers among the poor. However, new risks will emerge for several reasons. First, the marked sprawl of cities in the developing world will make access to care more difficult. Second, increasing motor vehicles and the likelihood of inadequate infrastructure will make air pollution and accidents in road traffic more common than in the past. Third, impoverished urban populations have already shown a propensity toward undernourishment, and its obverse, obesity, is already emerging as a major risk. Also, the large projected increase in slums suggests that violence and homicide will become a more important burden of health, and very large hazards will be created by fire-prone, insubstantial dwellings that will house nearly two billion people by 2030. In addition, decentralized governance will exacerbate the tensions and discontinuities that have plagued the management of health issues on the urban fringe over the past decade. Accordingly, public health agencies will need to adjust to the regional and country-specific factors to address the changing profile of risk. This analysis suggests that four factors - levels of poverty, speed of city growth, sprawl in cities, and degree of decentralization - will have importance in shaping health strategies. These factors vary in pace and intensity by region, suggesting that health care strategies for Category II and III conditions will need to be differentiated by region of the world. Also, interventions will have to rely increasingly on actors outside the ranks of public health specialists.
\end{abstract}

KEYWORDS Future urban growth, Injury, Noncommunicable disease.

\section{RISK, HAZARD, AND VULNERABILITY IN CITIES}

Category 1 conditions, communicable diseases, have been the central focus in public health for the past half century. Lopez et al. ${ }^{1}$ report that infectious and parasitic diseases account for more than $16 \%$ of the more than 50 million deaths and an equal proportion of the 1.54 billion disability-adjusted life years (DALYs) for low- and middle-income countries in 2001. These diseases - respiratory, diarrheal, tuberculosis, and malaria - have the heaviest impact on the poor in lowincome settlements around the world. Taken together, infectious and parasitic slum diseases would rank at the top of all categories of death.

\footnotetext{
Tim Campbell, PhD is Chairman of the Urban Age Institute, San Rafael, CA, USA; Alana Campbell is a consultant on environmental and public health issues, Washington, DC, USA.

Correspondence: Tim Campbell, Urban Age Institute, Chevy Chase, MD, USA. (E-mail: TimCampbell@ urbanage.org)
} 
At the same time, Lopez et al. report a striking drop in deaths in low- and middle-income countries due to communicable diseases-on the order of $20 \%$ over the past decade and close to $30 \%$ after discounting for the HIV/AIDS pandemic. If the gains in control over communicable diseases were to be consolidated - meaning that if current strategies of prevention and care continue to decrease the burden of communicable diseases - then it is likely that the public health community would need a shift in focus towards other risks.

The hypothesis in this paper is that the features of urbanization in the future will help determine which health issues get moved "up" in the list of the top 10 . Identifying emerging risks is based on two criteria. First, candidates for the list already hold important rank in global burden of death or DALYs (Table 1). Second, emerging risks must have some prima facie link to the features of future city growth-falling densities, the speed of urbanization, poverty and slum formation, and aging (Table 2).

Four issues meet these criteria. Violence and traffic injuries are measured directly as burdens of injury, disease, or death. Another two issues - obesity and settlement in unsafe areas (as well as pollution from increased vehicles) - are risk factors related to many other problems. All of these issues are already on the respective lists of top 10 burdens or risks. Unsafe settlement concentrates risk of natural hazards and disasters. Second, unlike other top 10 issues, these four are sensitive to physical conditions in growing cities.

The patterns of future urban growth will help make these issues emergent for reasons that are related to the mechanics, the geography, and the political dimensions of urban growth, as explained in the following section. However, other factors will also be at work. First, the strategic elements of the public health apparatus - the medical technology, training, tools like vaccinations and cold chains, and expertise of public health officials - is not completely "transferable" to the emerging class of problems. A somewhat different kind of apparatus will be needed, for instance in community peace making, planning of traffic and human settlements, and public education in nutrition.

\section{THE URBAN TRANSFORMATION—RISING CITIES IN CROSS-CURRENTS}

Many studies ${ }^{2-4}$ have shown not only that the planet is nearly urban but also that the urban population, on the average, is older and remains poor, that virtually all of the next two billion more people living in cities will occur in the developing part of the world, and that rural populations will remain essentially flat. Although terms like "population explosion" and "massive urbanization" are used often and rather loosely in the popular and even academic literature to describe the current picture, in reality, the fastest phases of urbanization have already passed.

\section{Pace of Growth}

Asia and Africa have the most impressive urban futures. The two Asian giants, India and China, account for most of the urban population on the planet. Both are less than $40 \%$ urban and both will produce the largest urban systems, coupled with the fastest economic growth in the world. Less appreciated is that the African continent has the fastest-growing cities. This is problematical because, unlike Latin America before it, and Asian countries at present, urban growth is taking place in advance of an industrial basis for growth. Unless national economies enjoy a 


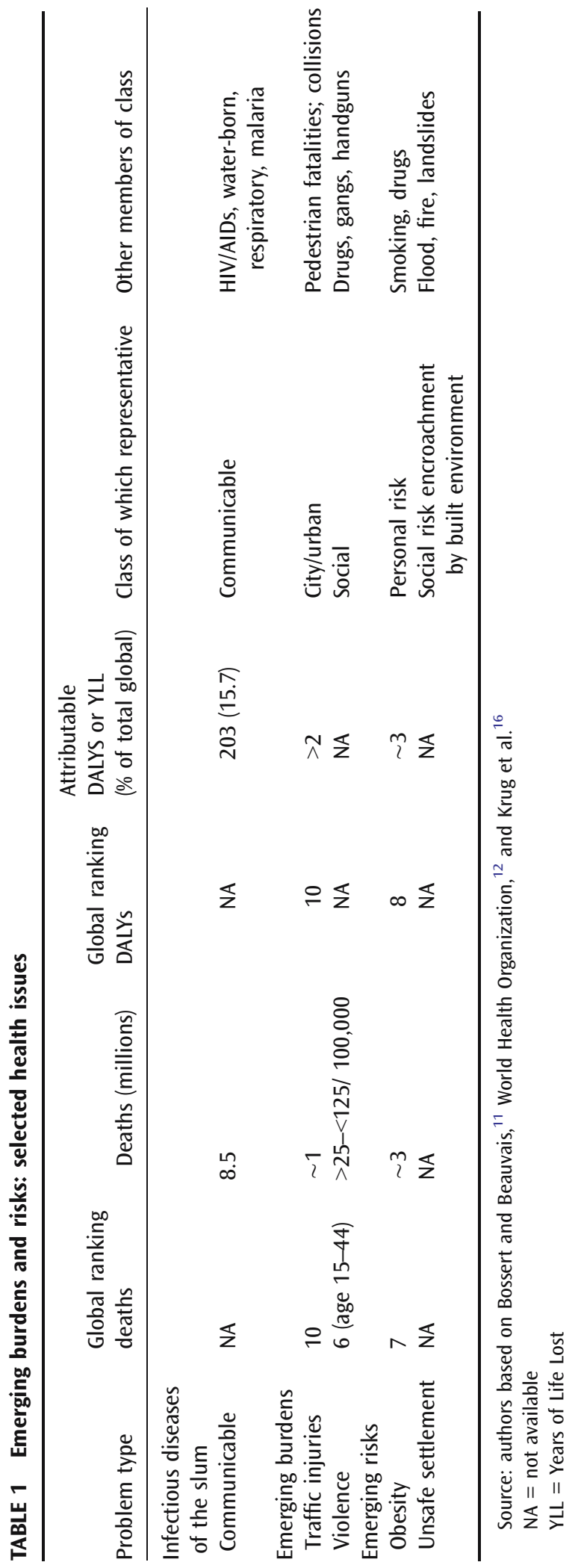


TABLE 2 Emerging health issues: notional variation with urban development

\begin{tabular}{lcccc}
\hline Problem type & $\begin{array}{l}\text { Varies with } \\
\text { urban growth }\end{array}$ & $\begin{array}{l}\text { Changes with spread } \\
\text { in city growth }\end{array}$ & $\begin{array}{c}\text { Presents risk } \\
\text { for the poor }\end{array}$ & $\begin{array}{l}\text { Varies with age } \\
\text { and gender }\end{array}$ \\
\hline Communicable diseases & High & Somewhat & High & $\begin{array}{c}\text { Somewhat } \\
\text { High }\end{array}$ \\
Traffic injuries & High & Somewhat & High & High \\
Violence & Somewhat & Somewhat & High & High \\
Obesity & Somewhat & Low & High & Somewhat \\
Unsafe settlements & High & High & High
\end{tabular}

Source: The table summarizes from the literature covered earlier in the article the direction and strength of relationship (high, somewhat, low) between each of the categories of burden (rows) and the key features of future urban growth (columns).

reversal of fortune - as they have, for instance, in China and India - the result will continue to concentrate poverty in cities.

\section{"Flattening" of Cities}

Perhaps the most notable finding in recent urban research is the discovery by Angel et al. ${ }^{5}$ based on satellite imagery that virtually all of the 120 cities sampled around the globe are beginning to sprawl outward. Although the degree of sprawl varies by region, the data form a consistent pattern globally. Average densities are falling in cities around the globe, and particularly in the developing regions. These observations are corroborated by data from East Asia. ${ }^{6,7}$ Webster $^{6}$ observes that settlements are taking place in administrative and jurisdictional "no man's land," the periurban areas conventionally defined as starting just beyond the contiguous built-up urban area and extending as far as $150 \mathrm{~km}$ from the core city center. Often, these areas lie in environmentally fragile zones, i.e., river banks, canal edges, and floodplains or worse, marginal land that is unstable and unsuitable for occupation.

The significance of these findings is in the implications this growth pattern holds for reduction in coverage of social and physical infrastructure, including facilities for primary and secondary health care, roads, and other services. Although many variations and exceptions to the pattern can be found, the overall trend is growth toward the periphery with lower coverage of physical infrastructure and social services.

\section{City Populations Older and Poorer}

Two other important socioeconomic features of growing cities - aging and poverty will have decisive effects on health care in the future. Although half the developing world population is under 25 , the youth segment of the population will move into older age brackets without being replaced at the rates of the past. Since the 1970s, fertility declines in virtually all regions, and particularly the least developed, have resulted in fewer people in the younger cohorts in rough proportion to the numbers of persons entering older age. The result is a drop by more than one-third in the proportion of people from 0-14 years of age, a distinct aging of the urban population. ${ }^{8}$

Poverty will continue to be a signal feature of many of the cities in the developing world, but with marked variations by region. The World Bank estimates that, on the whole, roughly $30 \%$ of urban populations live in poverty. ${ }^{9}$ However, the prospects for poverty vary strongly by region, as measured imperfectly by slum growth rate (Table 3 , first column). 
TABLE 3 Gross domestic product growth not sufficient to reach millennium development goals

\begin{tabular}{|c|c|c|c|c|}
\hline \multirow[b]{2}{*}{ Region } & \multirow[b]{2}{*}{$\begin{array}{l}\text { Slum growth } \\
\text { rate }^{2}\end{array}$} & \multirow[b]{2}{*}{$\begin{array}{l}\text { Average GDP } \\
\text { per capita 2000-2015 } \\
\text { (percent increase per year) }\end{array}$} & \multicolumn{2}{|c|}{$\begin{array}{l}\text { Percent population living on } \\
\text { less than one US\$/day }{ }^{32}\end{array}$} \\
\hline & & & Target percent & $\begin{array}{l}\text { Projection } \\
\text { to } 2015 \text { by } \\
\text { growth alone } \\
\text { percent }\end{array}$ \\
\hline East Asia & 2.28 & 5.4 & 14 & 1 \\
\hline Europe and C. Asia & NA & 3.6 & 1 & 1 \\
\hline $\begin{array}{l}\text { Latin America and } \\
\text { Caribbean }\end{array}$ & 1.28 & 1.8 & 8 & 8 \\
\hline $\begin{array}{l}\text { Middle East and } \\
\text { North Africa }\end{array}$ & -0.15 & 1.4 & 1 & 1 \\
\hline South Asia & 2.20 & 3.8 & 22 & 15 \\
\hline Africa & 4.53 & 1.2 & 24 & 35 \\
\hline
\end{tabular}

Adapted from World Bank. ${ }^{32}$

$\mathrm{NA}=$ not available

\section{Decentralization}

The most important cities on the planet are subject to many conflicting forces pulling policy attention in many directions. Political forces of decentralized governance push city leaders to attend to local needs of constituents and wishes of civil society often in opposition to national authorities, who aim to achieve different priorities. More than 70 countries around the globe are currently decentralizing, meaning they are passing on decision-making and spending powers to local governments. Nearly 25 republics in Latin America accomplished this change during the 1990s. ${ }^{10}$ Popular elections subject city decision-makers to a clamor for participation with which they have limited or no experience. Bossert and Beauvais ${ }^{11}$ illustrate these competing forces in public health as city and community leadership - mayors, elected officials, health sector professionals, and administrators - play more important roles in health care of many countries.

\section{EMERGING RISKS IN URBAN PLACES}

The results of these territorial, social, and political forces will have relatively greater effects on some burdens than others. Four issues are singled out as likely candidates of increasing burden.

\section{Road Traffic Injuries: Neglected Epidemic}

World Health Organization ${ }^{12}$ data reveal that, worldwide, the number of people killed in road traffic accidents is around 1.2 million, whereas the number of injured could be as high as 50 million, and these numbers are forecast to increase significantly in the coming decades. Road traffic injuries, urban and rural, ranked within the top 10 causes of death in $2001 .^{11}$ Developing countries account for more than $85 \%$ of all the fatalities and over $90 \%$ of DALYs lost due to road traffic injuries. For these reasons, the problems of road injuries and deaths are referred sometimes to the "neglected epidemic."13 
Deaths in traffic arise from poor traffic management and underdeveloped infrastructure, both of which pertain to low-income areas. Mixed traffic - animals, foot traffic, bicycles, small two- and three-wheeled vehicles, cars, delivery vans, and cargo trucks - all operate on the same roads, often in conditions that are poorly maintained and dimly lit. These circumstances, coupled with the inadequate investments in public transit and rapid urban growth are only part of the emerging risk to public health in cities. Pollution in air from diesel and two-stroke engines and the high number of motor cars also threaten to increase the disease burden, with impacts felt more widely and over a longer term than injury from poorly regulated traffic. Gosham ${ }^{14}$ reports that substantial fractions of air pollutants are emitted by automobiles in cities of the developing world. World Bank projections indicate that motorized vehicles in cities will increase by a factor of four worldwide by $2050 .^{15}$

A major question is whether infrastructure - lighted roadways with lanes to segregate traffic coupled with signaling systems - can keep pace with city growth. The lagging points are typically on the periphery where most cities are now growing with the greatest speed. Accessible treatment and trauma care is also critical for the worst injuries. ${ }^{13}$ However, trauma clinics are expensive and need to be placed strategically, always with a tradeoff of coverage and access time. Infrastructure of this kind generally lags some years behind city growth, especially in the lowestincome countries, suggesting that traffic injuries are likely to be a growing factor in the health burden in cities of the developing world.

\section{Urban Violence}

Many kinds of physical and nonphysical violence haunt the world of the urban poor. The landmark report on violence by $\mathrm{WHO}^{16}$ and more region-specific work ${ }^{17}$ cover a wide gamut of issues, including youth, child abuse, the elderly, sexual and collective violence, and others. For purposes of this paper, the focus will be on the health burden from death and injury in cities in relation to violence from civil sources.

Although inadequate in many ways, homicide rates are the most immediate and practical way to measure the burden of violence. The WHO report on violence indicates that, for the 15-29 age group, interpersonal injury ranks just below traffic fatalities. In specific countries and cities, these rates are high and growing, ranging from under 10 to over 100 per 100,000 population in some cities. A 2002 study in Sao Paulo found that the homicide rate was highest among young adult males (121 per 100,000). ${ }^{18}$

Many authors agree on factors that are associated with violence, including the growing segment of unemployed youth in the population; rising awareness of inequalities; the need for identity and defense, for instance in gangs; and past history of conflict. ${ }^{17,18}$ Krug and Moser cite drugs and handguns as factors in lethality, and Moser postulates a causal link connecting individuals, communities, institutions, and states, each level having some part to play in producing - and in remedying - violent behaviors.

Still other correlates to violence - for instance, poor health and individual and community dysfunction - have been accorded less attention. Research findings have linked violence to many deleterious effects on health, and many possible causal pathways, for instance, to both objective and subjective measures of socioeconomic status. ${ }^{19}$ Violence and poverty may have still wider impacts in the form of depression and defiant conduct disorders. These are known to be among the 
consequences of a violence-prone environment and have been observed in clinical settings in $\mathrm{Rio}^{20}$ and are a matter of clinical acceptance in the USA. ${ }^{21}$

As with other health issues, prevention, education, and integrated treatment strategies are forms of community help and civic involvement that incorporate psychological and social factors. These arise repeatedly in the literature as preferred forms of treatment. ${ }^{17,18,22}$ Tactics such as early closing of nightclubs and bars, gun control (but not buy-back programs), community awareness programs, and community policing have all been developed, some with good success. From the standpoint of treatment, trauma centers are expensive to maintain and likely to be more difficult to reach as cities spread with lower-density settlements. Prevention is clearly the most cost-effective pathway, yet this strategy also requires an organized civil society, high levels of social capital, and vision with leadership that, although proven to be effective, is also only beginning to develop in many decentralized local governments.

\section{Obesity}

Obesity is emerging as a potentially widespread threat to life and health in developing cities. Obesity is defined as having a body mass index greater than 30 . Obesity is ranked near the bottom of the top 10 risk factors for mortality and DALYs due to noncommunicable diseases. ${ }^{1}$ The prevalence of obesity has increased, overtaking malnutrition by a factor of two around the globe. Lopez et al. calculate that this group of diseases already caused over a million deaths and more than $3 \%$ of the 1.54 billion DALYs in $2001 .{ }^{1}$ Currently, one billion adults in the world are overweight. ${ }^{23}$ As a predictor for cardiovascular disease and for diabetes, obesity, as a risk factor, contributes greatly to mortality and loss of healthy years (see Dixon in this volume). In some households, obesity and malnutrition exist concurrently. ${ }^{24}$

The recent global increase in obesity stems from the coalescence of complicated factors. Urban lifestyle is one of them because of changes in food and activity level. The lifestyle factors are linked to reduction in energy expenditure. Compared to rural areas, less physical effort is required in city living. Additionally, food options change. Higher-caloric and fatty foods are cheaper and more widely available in cities. There is the potential to surpass caloric requirements and still incur nutritional deficits. ${ }^{25}$ This trend, the nutrition transition, plays the yang to the ying of physical activity in the balance of energy. ${ }^{26}$ Socioeconomic status and education level are central determinants to healthy weight. ${ }^{27}$

Several biological pathways, including heritability, can lead to unhealthy weight and obesity problem. ${ }^{28}$ As such, many of the greatest biological risks are mediated by environmental factors, especially early in life. For instance, new evidence suggests that an undernourished pregnancy can trigger a biological response that would impair the ability of a child to correctly process an influx of food. ${ }^{28,29}$ The risk that this and other biological factors could be compounded by environmental factors of urban lifestyles-the reduction in physical exertion and exposure to higher-caloric foods-could lead to a rise in the incidence of overweight and obese children.

\section{Unsafe Settlements}

Although data are not available to rank the risk of loss to, say, violence, obesity, or traffic injury, unsafe settlements have been involved in the most spectacular urban calamities of the century. Future trends in city growth appear if anything to 
exacerbate rather than attenuate the risks of injury and harm. De Ville de Goyet, Zapata, and Osorio feel that "in line with the definition of health adopted in the constitution of the World Health Organization (WHO), this section treats disasters as a health condition or risk, which, as any other 'disease,' should be the subject of epidemiological analysis, systematic control, and prevention, rather than merely as an emergency medicine or humanitarian matter."30 The central problem is that lowincome settlements around the globe consist of buildings with insubstantial and fireprone materials, poor foundations, and hazardous locations. ${ }^{2}$

One of the few estimates available ${ }^{30}$ indicates that urban disasters have affected an average of more than 700,000 persons per year for the Latin America region over the past 20 years; estimates from the Inter-American Development Bank (2004) for Colombian municipalities alone reached around half a million per year between 1981 and 2000. ${ }^{31}$ The number of deaths is not large, compared to other causes, but the pervasive long-term damage in injury and trauma is potentially large, but has not been measured.

Reducing the risk of unsafe settlements is perhaps the most obvious example of the need to incorporate a wide variety of policy and technical skills, outside of public health specialties, to achieve risk reduction. The poor settle in marginal lands - often subject to flood, landslide, or fire - for economic and political reasons. A third or more of the two billion people to be added to cities over the next few decades will live in slum or slum-like conditions. Adequate safe shelter is not available to them at any price they can afford. The poor are obliged to trade off the low cost of land for high vulnerability in risky areas. According to UN-Habitat, only a handful of countries are on track to reduce or reverse slum growth. ${ }^{3}$

\section{SHIFTING BURDENS OF CARE-MADNESS AND GENIUS OF CITIES}

\section{Tackling Emerging Burdens-Balancing Risks and Responsibilities}

Public health strategies will need to give more attention to the physical hazards for the urban poor in the coming decades. Officials and practitioners in the health and urban sectors will need to make many adjustments in priority setting and deploying resources. First, the focus of efforts needs to be on the poor, with more than one billion living on a dollar per day. The poor make up the largest fraction of slum residents and pedestrians and are the most common victims of violence and disasters. They also are overrepresented among the overweight and obese.

Second, emerging burdens will require a retooling of strategies for health care. The institutional and technological advances that have helped to achieve the striking reduction in communicable diseases over the past decade are only partly applicable to noncommunicable diseases and injury in the future. Addressing emerging burdens will require interventions from a much wider array of public sector actors than in the past, including infrastructure planning and design in roads, land use planning and siting of buildings and community settlements, and community development and public education specialists to deal with violence and obesity.

Third, safety and community-oriented concerns take on a more important dimension in health. In all the issues, the neighborhood and community ties represent an important resource in prevention and treatment. Many social 
TABLE 4 Nature of urbanization and implications for health care by region

\begin{tabular}{|c|c|c|c|c|c|c|}
\hline Urban factors & Africa & $\begin{array}{l}\text { Middle East } \\
\text { and North Africa }\end{array}$ & $\begin{array}{l}\text { Europe and } \\
\text { Central Asia }\end{array}$ & Latin America & South Asia & $\begin{array}{l}\text { East } \\
\text { Asia }\end{array}$ \\
\hline $\begin{array}{l}\text { Rate of urban } \\
\text { growth }\end{array}$ & High & Low & Low & Mod & High & High \\
\hline Sprawl & Low & Mod & NA & Low & High & High \\
\hline $\begin{array}{r}\text { Decentralized } \\
\text { governance }\end{array}$ & Low & Low & NA & Mod & Mod & \\
\hline Poverty & High & Low & Low & Low & Mod & Mod \\
\hline
\end{tabular}

Source: In any given category in the respective sources. "High" refers to the top third in any category, "Mod" refers to the middle third, and "Low" refers to the bottom third of their respective sources. The indicator "Rate of urban" was taken from the National Research Council; "sprawl" was taken from Angel et al.; "Poverty" is a reflection of the rate of slum formation by region from Table 1, column 1; and "decentralization" is a relative measure that compares each of 50 countries against a common standard from Arzaghi and Henderson. ${ }^{37}$

$\mathrm{NA}=$ data not available

programs - for instance, in midwifery, HIV/AIDs treatment, oral rehydration, and diarrheal diseases - have demonstrated the importance of information and education strategies that make use of small group settings near residences and take advantage of oral and visual (as opposed to written) materials. Many lessons can be drawn from these experiences; for instance, differentiating responses to match levels of need and understanding and involving communities in identifying problems and formulating and implementing solutions. ${ }^{32,33}$

Fourth, international agencies like WHO, World Bank, and UN-Habitat need to tailor strategies to address emerging health risks in accordance with the specific circumstances of each of the main regions of the world. Each region is characterized by differences in the key factors of future urban growth (Table 4) that affect burdens of health. The table suggests that the level of poverty, speed of urbanization, deficits in infrastructure, and experience with decentralization are four markers that will help to make decisions about strategy in public health.

Finally, although cities concentrate problems and accentuate risks, they are also the cauldrons of innovation, and they are beginning to learn from each other. Many cities have already engaged in city-to-city exchange, conferring on such issues as healthy cities, trade, economic development, environmental sustainability, and finance, to name a few. The horizontal assistance is a phenomenon that already likely amounts to a shadow economy of knowledge. ${ }^{34}$ The United Nations Development Program asserts that links between cities over the past several decades number in the range of 15,000 to 20,000 , and city-to-city cooperation has become a recognized field of development assistance. ${ }^{35,36}$ Strategies for emerging burdens should explore this vehicle of horizontal learning among cities as a way to leverage the limited resources of international agencies.

\section{ACKNOWLEDGEMENTS}

The authors wish to gratefully acknowledge support from WHO Kobe for the preparation of this article. 


\section{REFERENCES}

1. Lopez A, Mathews C, Ezzati M, Jamison DT, Murray CJL. Global and regional burden of disease and risk factors, 2001: systematic analysis of population health data. Lancet. 2006;347:1747-1757.

2. National Research Council. Cities Transformed. Washington, DC: National Academies Press; 2003.

3. UN-Habitat. The State of the World's Cities 2006/2007. The Millennium Development Goals and Urban Sustainability. London: United Nations and Earthscan; 2006.

4. UN-Habitat. The State of the World's Cities 2004/2005. Globalization and Urban Culture. London: United Nations and Earthscan; 2004.

5. Angel S, Sheppard S, Civco D. The Dynamics of Global Urban Expansion. Transport and Urban Development Department. Washington, DC: World Bank; 2005.

6. Webster D. Urbanization Dynamics and Policy Frameworks in Developing East Asia. Working paper no. 8, Urban Development Sector Unit. East Asia. Washington, DC: World Bank; 2003.

7. World Bank. Sustainable Development on the Urban Fringe. Economic and Sector Analysis. East Asia and the Pacific Environment Department. In press, 2007.

8. United Nations. World Population Prospects. The 2004 Revision. New York: United Nations; 2004.

9. World Bank. Cities in Transition. World Bank Urban and Local Government Strategy. Infrastructure Department. Washington, DC: World Bank; 2001.

10. Campbell T. The Quiet Revolution. Decentralization and the Rise of Political Participation in Latin American Cities. Pittsburgh: University of Pittsburgh Press; 2003.

11. Bossert T, Beauvais J. Decentralization of health systems and Ghana, Zambia, Uganda, and the Philippines: a comparative analysis and decision space. Health Policy Plan. 2002;17(1):14-31.

12. World Health Organization. World Report on Road Traffic Injury Prevention. Geneva: World Health Organization; 2004.

13. Nantulya VM, Reich MR, et al. Report of the Road Traffic Injuries and Health Equity Conference. Cambridge: Harvard Center for Population and Development Studies; 2002.

14. Gorham R. Air Pollution from Ground Transportation. An Assessment of Causes, Strategies and Tactics, and Proposed Actions for the International Community. New York: United Nations, Division of Sustainable Development, Department of Economic and Social Affairs; 2002.

15. World Bank. World Bank East Asia and the Pacific Urban Business Directions. Washington, DC: World Bank, East Asia Department; 2004.

16. Krug E, Dahlberg L, Mercy J, Zwi A, Lozano R. World Report on Violence and Health. Geneva: World Health Organization; 2002.

17. Moser C, van Bronkhorst B. Youth Violence in Latin America and the Caribbean: Costs, Causes, and Interventions. LCR Sustainable Development Working paper no. 3, Urban Peace Program Series. ESSD. Latin America and Caribbean Region. Washington, DC: World Bank; 1999.

18. Gizewski P, Homer-Dixon T. Urban Growth and Violence: Will the Future Resemble the Past? Occasional paper, Project on Environment, Population, and Security. Washington, DC: American Association for the Advancement of Science and the University of Toronto; 1995.

19. Harpham T, Stephens, C. Policy directions in urban health in developing countries-the slum improvement approach. Soc Sci Med. 1992;35(2):111-120.

20. Andrade, RC, Silva, VA., Assumpcao Jr, FB. Preliminary data on the prevalence of psychiatric disorders in Brazilian male and female juvenile delinquents. Braz J Med Biol Res. 2004;37(8):1155-1160. Available at: http://www.scielo.br/scielo.php?script=sci_ arttext\&pid=S0100-879X2004000800005\&lng=en\&nrm=iso. ISSN 0100-879X. DOI: 10.1590/S0100-879X2004000800005. 
21. Burke J, Loeber R, Brumaker B. Oppositional and defiant disorder and conduct disorder: a review of the past 10 years, part II. J Am Acad Child Adolesc Psychiatry. 2002;41:1275-1293.

22. Cano I, Santos N. Violencia Letal, Renda, y Desigualidade Social no Brasil. Rio de Janeiro: Editora Sete Letras; 2001.

23. World Health Organization. WHO Factsheet on Overweight and Obesity. Available at: http://www.who.int/dietphysicalactivity/media/en/gsfs_obesity.pdf. Accessed 13 Mar 2007.

24. Caballero B. A nutrition paradox-underweight and obesity in developing countries. $N$ Engl J Med. 2005;352(15):1514-1516.

25. Drewnowski A, Popkin BM. The nutrition transition: new trends in the global diet. Nutr Rev. 1997;55(2):31-43.

26. Caballero B, Rubinstein S. Environmental factors affecting nutritional status in urban areas of developing countries. Arch Latinoam Nutr. 1997;47(2):3-8.

27. Stunkard AJ. Factors in obesity: current views. In: Pena M, Bacallao J, eds. Obesity and Poverty: A New Public Health Challenge. Washington, DC: Pan American Health Organization; 2000:23-28.

28. Caballero B. Introduction Presented at the Symposium: Obesity in Developing Countries: Biological and Ecological Factors. San Diego: American Society for Nutritional Sciences; 2001.

29. Sawaya AL. Long-term effects of early malnutrition on body weight regulation. Nutr Rev. 2004;62(7):127-133.

30. de Ville de Goyet C, Marti RZ, Osorio C. Natural disaster mitigation and relief. In: Jamison DT, Mosley HW, Measham AR, eds. Disease Control Priorities. Washington, DC: World Bank; 2004:1147-1162.

31. Inter-American Devleopment Bank. Programa de Informacion de Indicadores de Gestion de Riesgos. Aplicacion de Sistema de Indicadores 1980-2000. Resumen de Resultados. Manizales, Colombia. Manizales: InterAmerican Development Bank, Economic Commission for Latin America and Instituto de Estudios Ambientales, National University of Colombia; 2004.

32. World Bank. Making Services Work for Poor People. World Development Report 2004. Washington, DC: Oxford University Press and World Bank; 2003.

33. Gillespie S. Scaling up community driven development: a synthesis of experience. Food Consumption and Nutrition Division Working paper no. 181. Washington, DC: International Food Policy Research Institute; 2004.

34. Blanco H, Campbell T. Social capital of cities: emerging networks of horizontal assistance. Technol Soc. 2006;28(1-2):169-181. Available at: http://www.sciencedirect.com/science/ journal/0160791X. Accessed 19 Feb 2007.

35. United Nations Development Program. "Linkages in Cities." UN Report on City to City Cooperation. New York: United Nations Development Program; 2001.

36. UN-Habitat. Partnership for Local Capacity Development. Experiences with City-toCity Cooperation. Nairobi: United Nations Habitat; 2003.

37. Arzaghi M, Henderson V. Why countries are fiscally decentralizing. J Public Econ. 2005;89:1157-1189. 